\title{
Multi-Phase Linear Generator for Electric Vehicle Applications
}

\author{
Claudiu Oprea ${ }^{1,}$, , Szabo Lorand ${ }^{1}$, Claudia Marțiș ${ }^{1}$ \\ ${ }^{1}$ Technical University of Cluj-Napoca, 28 Memorandumului st., Romania \\ a Claudiu.Oprea@mae.utcluj.ro
}

\begin{abstract}
Keywords: Linear Electric Generator, Free Piston Engine, Automotive, Permanent Magnet Machine
\end{abstract}

\begin{abstract}
The oil production peak and the major climatic changes due to global warming determined all the major vehicle manufacturers to focus their attention on new, non-polluting, energy efficient technologies. The electric vehicle seems to be the easiest to implement, the most important drawback being related to the available energy storage capabilities. The Hybrid Electric Vehicle was introduced as an intermediate step, using Internal Combustion Engines to the required electric energy produce on-site. A particular solution is using a Free Piston Engine - Linear Electric Generator with several advantages compared to classical solutions. The current paper presents a multi-phase linear generator topology, along with a novel design method and some FEM simulations that validate the design procedure.
\end{abstract}

\section{Introduction}

The beginning of this millennium is marked by the decision of virtually all major car manufacturers to invest in the research of electric and hybrid electric vehicles as an alternative to conventional fossil fuels powered units. Two major concerns determined this approach: climatic changes due to greenhouse gases emissions and the problems regarding the natural reserves of fossil fuels.

Extreme climatic phenomenon, the rising of the ocean level or higher multiannual average temperatures are all accounted on the greenhouse gases (GHG) emissions due to the use of petrol and other fossil based fuels for powering the modern society. A look at the multiannual average temperatures shows a constant increase since the middle of the $20^{\text {th }}$ century, with record temperatures around the year 2000. There is a high correlation between this and the concentration of GHG in the atmosphere, especially that of $\mathrm{CO}_{2}$ : Since de industrial revolution in the XVIII century UK the $\mathrm{CO}_{2}$ concentration has been rising constantly until the middle of the XIX century when it erupted, rising with almost $15 \%$ in only 50 years [1]. The $\mathrm{CO}_{2}$ has the highest concentration so it is important to determine its sources: $27 \%$ of the total $\mathrm{CO}_{2}$ are due to transportation and the majority of those are because of road transportation; two thirds of these are produced by small vehicles [2].

Another important factor that must be considered is the fact that, according to some researchers, the oil production will reach its peak in the following years (some say it already had [3]) and the remaining reserves will be depleted in the next 20 to 30 years, taking into account the fact that the world oil demand is expected to grow $50 \%$ by 2025 [4]. The most optimistic amongst us consider that this peak will not come in our life time, considering the "unconventional oil" that becomes available due to improvements in extraction technologies and that such reserves will become feasible when the "conventional oil" prices will become even higher. A recent article on this theme claims that by using such a new technology the western states could break loose from their dependence on Middle East oil and gas [5], although at a yet unknown environmental price. In this general context and within the frame of the Kyoto Protocol the renewable energy sector is rapidly gaining ground, research programs on this topic being founded at national and international level. Unfortunately the renewable energies cannot be applied to automotive applications due to their low energy density, so different solutions were proposed, including compressed air, hydraulic engines or electric motors, all involving specific problems, the biggest being to find a solution to store the energy required to power the drive train. Considering the fact that the electrical machines and power electronics are mature fields compared to the others and that an electric power supply can be found almost anywhere, most of the car manufacturers founded research programs focused on nonpolluting electric vehicles, with hybrid vehicles as an intermediate step. 
The major problem concerning the full electric vehicles is the electric power storage system, mainly batteries (lead-acid, $\mathrm{NiMH}, \mathrm{Li}-\mathrm{ion}, \mathrm{NiZn}$ or $\mathrm{NiCd}$ ) or ultracapacitors, offering various storage performances and different number of charge - discharge cycles [6]. A recent study shows that an investment in such an electric vehicle would not pay off, because of the high acquisition cost and the need of periodic battery replacement [7].

There are several solution used to combine the power generated by the internal combustion engine (ICE) and the electric motor inside a hybrid electric vehicle [8]:

- parallel hybrid - both power sources are connected to a mechanical transmission and simultaneously transmit power to drive the wheels; the hybrid can use regenerative braking to charge the battery pack; the first mass production car of this type was the Honda Insight

- series hybrid - only the electric motor powers the drive-train, while the ICE is used to power an electric generator to recharge the batteries so it can be regarded as an range extender; Toyota introduced the first HEV of this type in 1997 and other producers opted for with this topology in the latest years

- power-split hybrid - or series-parallel hybrid systems combine the advantages of the two basic types: the series hybrid are more efficient at low speed and the parallel configuration is better at high speeds; the most know is the Toyota Prius, with more than 3 million units sold worldwide.

The easiest and cheapest way to transform a conventional car into a series hybrid vehicle is to use the already installed conventional ICE and connected it to a rotating electric generator that would provide the required electric energy. A new solution was proposed were the electric power is produced using a linear electric generator directly coupled to a Free Piston Engine, and the propulsion of the vehicle is accomplished using in-wheel electric machines.

\section{The Free Piston Engine - Linear Electric Generator System}

In order to fully understand this new concept a few things about its components must be explained.

\section{Free Piston Engines}

The major difference compared to conventional ICE is the absence of the crankshaft that would transform the linear motion of the pistons inside the cylinders into rotational motion. The FPE can be of two major types, with internal combustion (the combustion takes place inside the cylinders) or external combustion engines, where a working fluid is heated in an external source and then flows through the cylinder (such as the steam engine or the Stirling engine) [9].

The original Internal Combustion Free Piston Engine was patented in 1928 by R.P. Pescara and was initially used for air compressors. Other manufacturers like Junkers in Germany, SIGMA in France, General Motors and Ford Motor Company in USA also showed their interest in this type of engines, but until the Second World War the FPE was exclusively used for producing compressed air and latter was abandoned for a while; the first system using it with a linear electric generator is reported in 1959. Reported internal combustion engine systems use both two-stroke and four-stroke combustion cycles, depending on the application [10].

The absence of a crankshaft brings the advantage of fewer moving parts and reduced friction between the piston and the cylinder walls, but also requires an additional device that would store the mechanical work produced by the piston during the power stroke and return some of that to prepare the system for a new cycle. This rebound device could be a mechanic spring, a compressed air cylinder or an electric linear device. Depending on the number of piston and their position there are several possible topologies:

Single piston - uses only a combustion chamber and a rebound device to store part of the energy generated during the combustion stroke. This device allows the control of the system frequency and stroke by controlling the low and high pressure valves;

Dual piston - eliminates the need of a rebound device during functioning because the combustion stroke of one piston coincides with the compression stroke of the second piston. An external force needs to be applied when starting the engine, a force that can be produced by the linear electrical machine. The high vibration levels produced by such a system can be eliminated by using two or more systems that would work in anti-phase, requiring precise control. 
Opposed piston - the two pistons share the same combustion chamber and a mechanical synchronization part that assures that the pistons move simultaneously is needed. Each piston requires a rebound device on the free shaft end and the load (the electric generator) may be mounted on each side [10].

A Linear Electric Generator directly connected to a dual piston FPE is shown in Fig. 1. Such a system would require complicated control of the intake and exhaust ports in order to obtain higher efficiencies and lower $\mathrm{NO}_{x}$ and $\mathrm{CO}_{2}$ emission levels than in conventional IC engines.

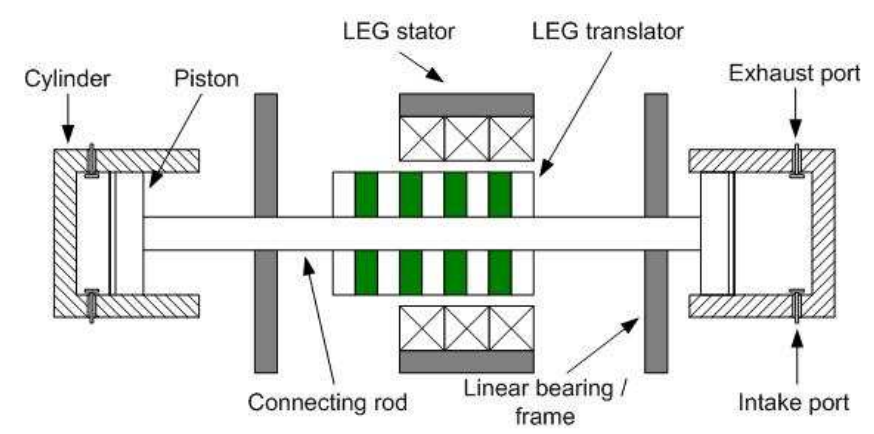

Figure 1. Free Piston Engine - Linear Generator System

Free piston internal combustion engines provide better dynamic profiles compared to conventional crankshaft internal combustion engines, can work at variable compressed ratio and, by limiting the temperatures inside the combustion chamber, produce less pollution. Fig. 2 presents the piston motion profile and the speed profile for a free piston engine and a conventional engine working at similar frequencies [11]. During the combustion stroke the expansion of the free piston is faster compared with a conventional engine and the time spent around the TDC (Top Dead Centre) is shorter, meaning the speed is also higher around TDC.

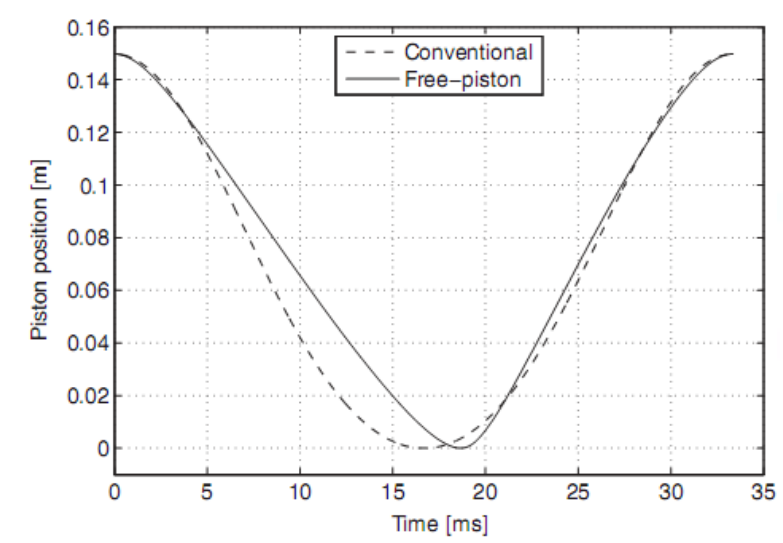

a) Piston motion profiles

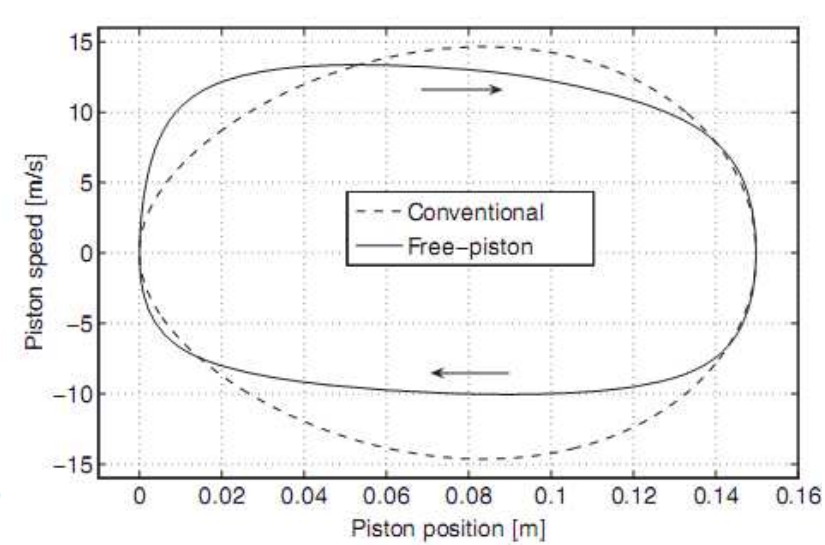

b) Piston speed profiles

Figure 2. Piston dynamics of a conventional and FPE [11]

\section{Linear Electric Generators}

Numerous papers were published on this topic in the last years, proposing several electrical machine topologies: PM synchronous machines, PM variable reluctance machines, TFM, hybrid Vernier machines, air-cored machines and moving coil machines [12-18], each of them providing advantages and disadvantages. Because of the specific application some aspects must be considered: high energy densities must be obtained, so rare-earth PM should be used, the electrical machine must be able to work both as a motor and as a generator, so a multi-phase structure is required, temperatures near the combustion chambers can reach up to $400{ }^{\circ} \mathrm{C}$ so thermal insulation is required. In the same time, in order to obtain performances similar to those inside rotational generators, the linear speed of the translator must be very high, so oscillating frequencies of $30 \mathrm{~Hz}$ are usually referred, resulting in the need to design a low-weight translator. 
A variable reluctance generator could suit these requirements, but the low energy density and the complicated electronics makes it unattractive for our study; instead a structure with PM on the translator is considered that could prove itself a viable solution, given that a way to thermally insulate the FPE and the LEG is found and that the rear-earth PM prices will return to lower levels. Tubular structures are usually preferred, due to the reduction of magnetic forces thanks to the symmetry, but the construction of such a structure is rather difficult; instead a hexagonal section structure is presented, based on the similar results obtained when a comparative study on a tubular and a square section generators was performed [19]. The translator of the structure is presented in Fig. 3, containing a non magnetic shaft with circular section several magnetic material poles mounted on this shaft and permanent magnets mounted between the poles. The permanent magnets are axially magnetized and mounted alternatively, so that the magnetic flux lines are forced to go through the poles towards the air gap.

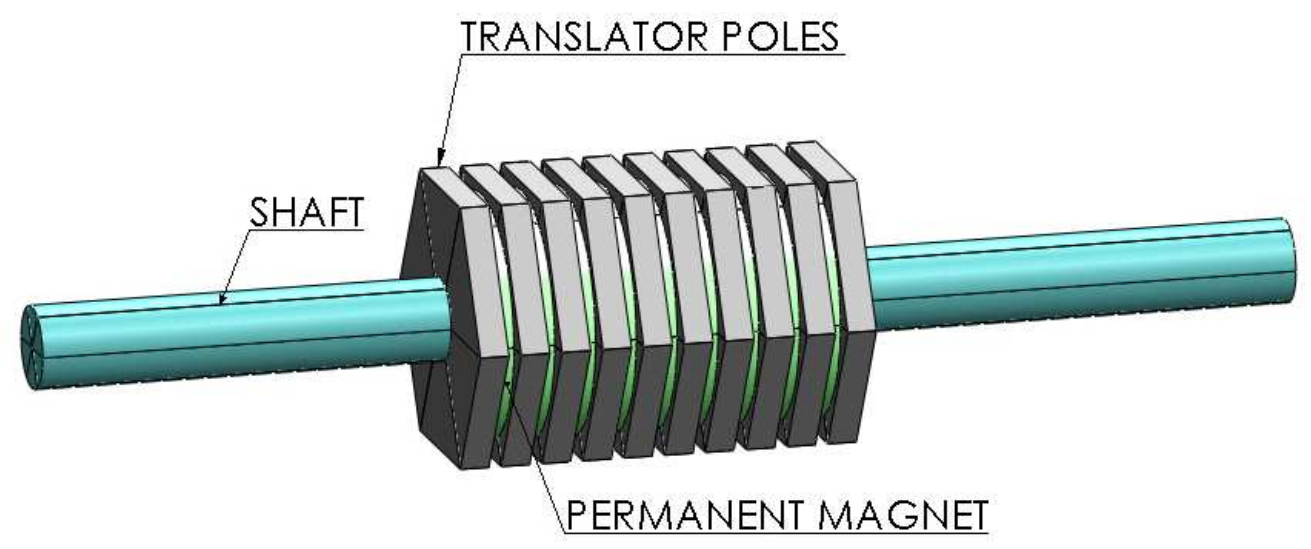

Figure 3. Translator of the linear generator

The generator stator is made up of 6 distinct parts, mounded around the translator. Two topologies were considered, with the coils mounted around the stator yoke, allowing a higher number of turns to be used, but only using a part of the magnetic flux density produced by the permanent magnets and the second with the coils mounted around the stator tooth, with smaller number of turns/coil and higher magnetic flux density. Both structures, presented in Fig. 4, were considered for a preliminary analysis and the results pointed toward the structure with the coils mounted around the teeth, offering higher power/volume ratio.

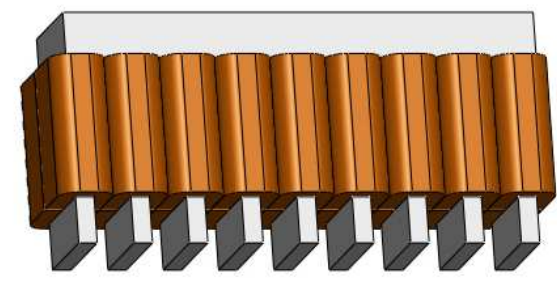

a) Coils mounted around the teeth

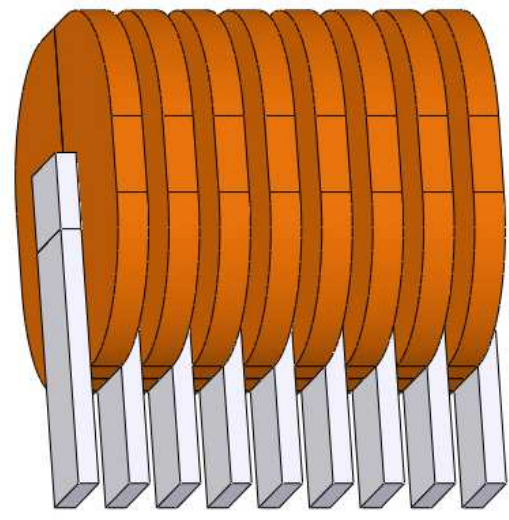

b) Coils mounted around the yoke

Figure 4. Stator of the linear generator

Depending on the way the six parts are mounted the generator can provide two, three or six phase symmetrical voltage systems or just one voltage if all the coils are connected in series. Because most commercially available electronic converters are build for three phase systems the 
generator will be used by mounting each stator in pair with the one opposing it, while the other two pairs are mounted with an offset equal to one third of the pole pitch. A simplified image of the structure is presented in Fig. 5, with the translator in the leftmost position. Since there is no magnetic flux passing through the coils on the right side, these are not producing energy, but instead act as an additional load (since all the coils are connected in series). To eliminate this problem the coils that are inactive should be disconnected using an appropriate control. Another solutions is to build a longer translator, so that the coils would be active at all times, at the expense of a higher moving mass, with negative influence on the FPE performances.

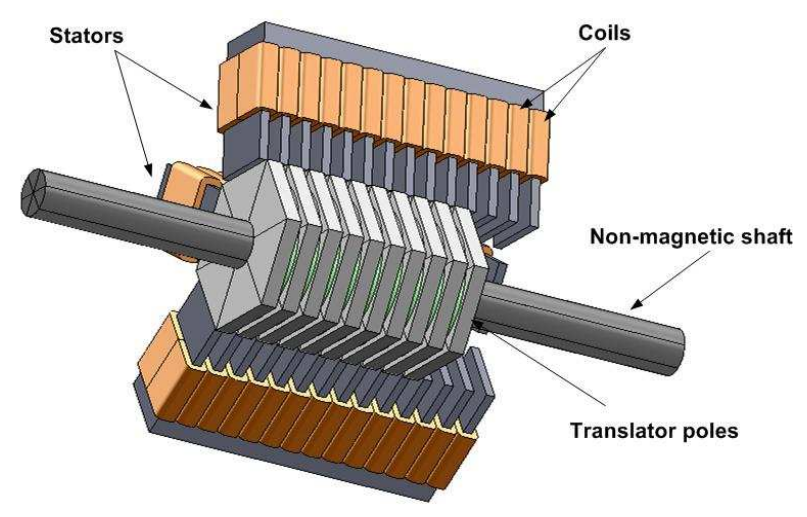

Figure 5. 3D model of the six-side linear generator

\section{Design of the Linear Electric generator}

The design procedure is based on some simple equations, used for determining the average linear speed of the translator, induced voltage, number of turns and other parameters. Eq. 1 determines the average speed as a function of the total translator stroke and the frequency of the movement:

$$
u_{a v}=2 \cdot l_{\text {stroke }} \cdot f \text {. }
$$

The generated phase voltage is given by Eq. 2:

$$
V_{R M S}=B_{c} \cdot u_{a v} \cdot N_{c} \cdot l_{c}
$$

where: $\mathrm{B}_{\mathrm{C}}$ is the average magnetic flux density passing through the coil, $\mathrm{N}_{\mathrm{C}}$ is the number of turns/phase and $l_{C}$ is the average length of one coil turn. The total number of turns for one phase depends on the number of turns in one coil, $\mathrm{n}_{\mathrm{t}}$, number of coils/stator, $\mathrm{n}_{\mathrm{c}}$ and the number of stators connected in series, $\mathrm{n}_{\mathrm{s}}, 2$ in the case of a 3-phase six-side stator.

$$
N_{c}=n_{t} \cdot n_{c} \cdot n_{S}
$$

Starting from this equations and the magnetic equivalent circuit (MEC) for a section of the generator, presented in Fig. 6, the geometric dimensions of the generator can be determined if initial values are set for the power, voltage, speed, efficiency, stroke length and permanent magnet type. From the MEC the magnetic flux density in all the parts of the generator can be determined and the induced voltage in the coils can be approximated. The reluctances $R$ and the fluxes $\Phi$ are represented for all the parts of the structure: $s h$ - the shaft, $p s h$ - translator pole area near the shaft, $p m$ - the permanent magnet, $p 1$ - translator pole in the area situated between the permanent magnets (with curved flux lines), $t$ - the air between the translator poles, $p 2$ - translator pole area near the air gap (parallel flux lines), $g t$ - a thin air gap region near the translator, $g$ - the air gap, $g s$ a thin air gap region near the stator, $t 1$ - the stator tooth near the air gap (in the area with no coils in the slot), $c$ - the slot (through the coil), $t 2$ - the tooth in the coil area, $y$-yoke and $\Theta_{p m}$ - permanent magnet MMF. 


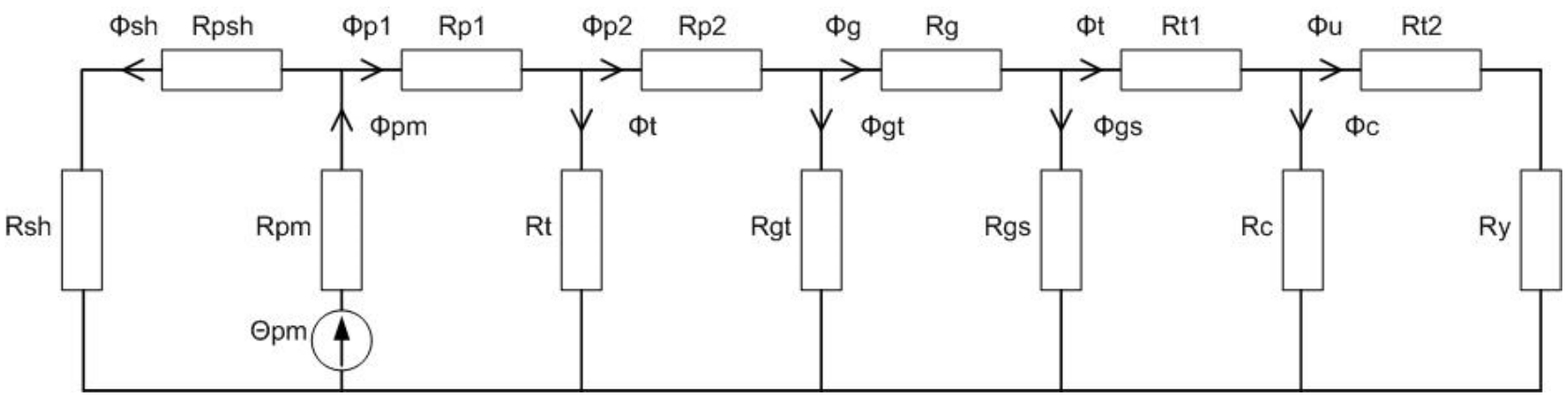

Figure 6. Magnetic equivalent circuit

The equations required for solving the MEC were implemented in LabVIEW, a visual programing language which was best suited for our application. For each branch of the MEC the magnetic flux, magnetic flux density and reluctance are shown, along with information regarding the amount of the PM flux that flows through the branch.

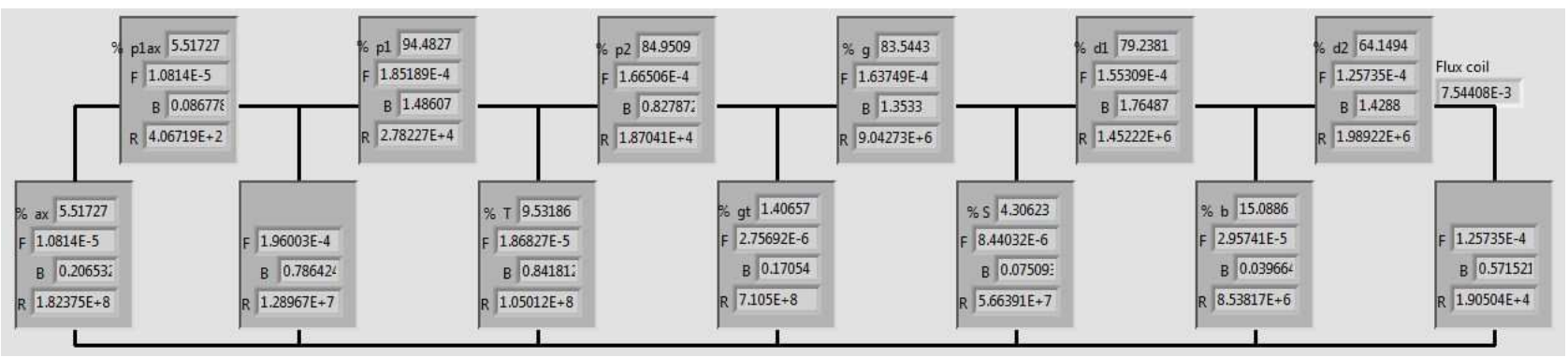

Figure 7. Magnetic equivalent circuit implemented in LabVIEW

In order to validate the MEC approach, a 3D model of the structure was implemented in Jmag Studio, a Finite Element Method based software that allows static or dynamic simulations. Only one sixth of the structure was considered and symmetric boundary conditions were imposed. To further reduce the simulation time only 5 coils and 7 translator poles were considered. The magnetic flux density distribution (an axial cut plane was considered through the middle of structure) is presented in Fig. 8, with values similar to those obtained using the equivalent magnetic circuit approach.

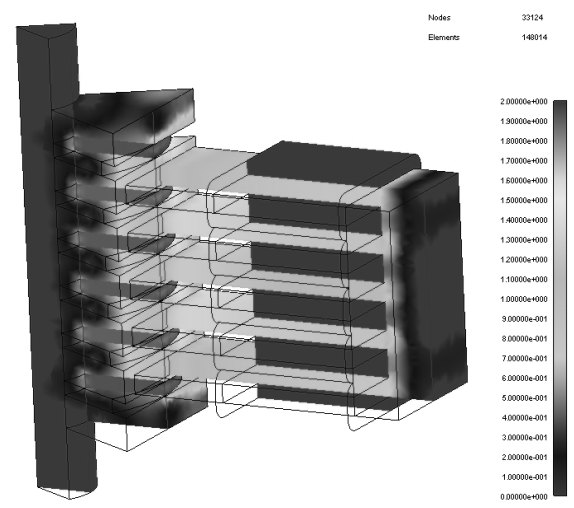

Figure 8. Magnetic flux density repartition in a 3D model

Some constrains are imposed: output power, average speed, efficiency, stroke length, pole pitch, residual magnetic flux density or coercive magnetic field strength or number of coils; the other geometric dimensions are automatically determined. If any parameter is changed some oscillations appear because of the modification of the permeability in the MEC branches. An additional program that allows the automatic variation of several geometric dimensions between specified limits serves as an input for the MEC and the result are stored in text files. For example, if the PM radius is varied between 20 and $26 \mathrm{~mm}$, the shaft radius is varied between 8 and $11 \mathrm{~mm}$ and the 
load current is varied between 0 and $4 \mathrm{~A}$ the 140 possible cases are solved in a few minutes and the results can be visualized. Fig. 9 a) presents the variation of the phase voltage for different values of the PM radius and shaft radius, while Fig. 9 b) shows the phase voltage variation when the shaft radius remains constant and the load current varies.

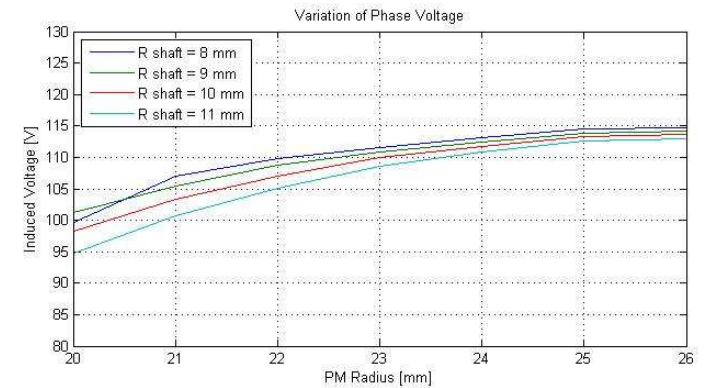

a) Load current constant, $R$ shaft varied

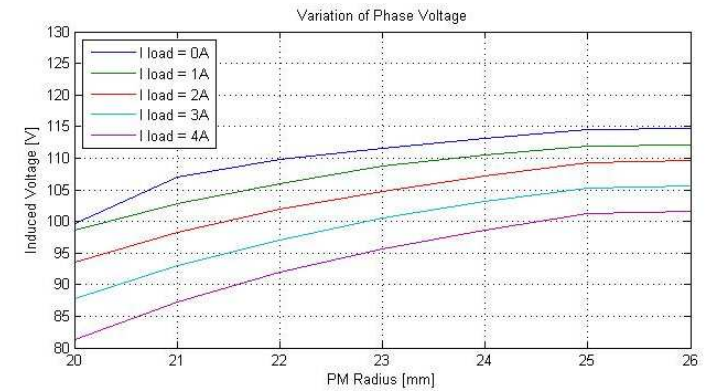

b) R shaft constant, load current varied

Figure 9. Induced voltage

\section{Conclusions}

In the frame of increasing concerns regarding the climatic changes and uncertainties on oil reserves and prices the major vehicle manufacturers developed hybrid electric vehicles as an intermediate step for full electric vehicles. A different solution for providing the electric energy for series hybrids is using a Free Piston Engine - Linear Electric Generator system with superior reported results compared to conventional ICE - electric generator systems. Some basic information was presented about FPE and the linear generator solution was introduced.

A generator with hexagonal section is considered with permanent magnets mounted on the translator and six independent stators, transforming the structure into a one-, two-, three- or sixphase generator, depending on the desired performance and available electronics. The six-stator structure has the advantage of reducing the undesired magnetic forces because of its symmetries and is easier to build compared to tubular structures.

The paper presents a different design approach, based on a magnetic equivalent circuit of the structure implemented in LabVIEW, allowing fast results for various geometric dimensions of the structure and a fast optimization of the structure using common algorithms. The results were confirmed using a commercial FEM software, Jmag Studio, both in static and dynamic analysis.

\section{Acknowledgement}

This paper was supported by the project "Development and support of multidisciplinary postdoctoral programmes in major technical areas of national strategy of Research - Development Innovation" 4D-POSTDOC, contract no. POSDRU/89/1.5/S/52603, project co-funded by the European Social Fund through Sectoral Operational Programme Human Resources Development 2007-2013.

\section{References}

[1] S.E. Schwartz, The Greenhouse Effect, Brookhavem National Laboratory, Atmospheric Sciences Division, CSSP Lecture (2005). Available online: http://www.ecd.bnl.gov/steve/pop/greenhouse_effect-2005.pdf.

[2] OECD (Organization for Economic Co-operation and Development), "Strategies to Reduce Greenhouse Gas Emissions from Road Transport: Analytical Methods”, report, (2002). Available online: http://www.internationaltransportforum.org/pub/pdf/02GreenhouseE.pdf

[3] P. Roberts, The End of Oil. On the Edge of a Perilous New World. With a new afterword. Boston: Mariner Books, 2005. 
[4] R.L. Hirsch, R. Bezdek, R. Wendling, Peaking of World Oil Production: Impacts, Mitigation, \& Risk Management, Available online: http://www.netl.doe.gov/publications/others/pdf/oil_peaking_netl.pdf.

[5] N. Lawson, Thought we were running out of fossil fuels? New technology means Britain and the U.S. could tap undreamed reserves of gas and oil, Published 7 December 2012, Available online: http://www.dailymail.co.uk/debate/article-2244822/Thought-running-fossil-fuels-Newtechnology-means-Britain-U-S-tap-undreamed-reserves-gas-oil.html.

[6] A. Khaligh, Li Zhihao,Battery, Ultracapacitor, Fuel Cell, and Hybrid Energy Storage Systems for Electric, Hybrid Electric, Fuel Cell, and Plug-In Hybrid Electric Vehicles: State of the Art, IEEE Transactions on Vehicular Technology, Volume 59, Issue 6, pg. 2806 (2010), ISSN: 0018-9545.

[7] P.E Ross, Loser: Why the Chevy Volt Will Fizzle, IEEE Spectrum special report, Volume 47, Number 1 international, January 2010.

[8] C.C. Chan, The State of the Art of Electric Hybrid, and Fuel CellVehicles,Proceedings of the IEEE, Volume 95, Issue 4, pg. 704-718, ISSN : 0018-9219.

[9] W.M. Arshad., T. Backstrom, P. Thelin and C. Sadarangani, Integrated Free-Piston Generators: An Overview, IEEE NORPIE-02 Conference, Stockholm, 2002.

[10]R. Mikalsen, A.P. Roskilly, A review of free-piston engine history and applications, Applied Thermal Engineering 27, (2007): 2339-2359.

[11]R. Mikalsen, A.P. Roskilly, The fuel efficiency and exhaust gas emissions of a low heat rejection free-piston diesel engine, Proceedings of the Institution of Mechanical Engineering, Part A: Journal of Power and Energy, pag 379-386, Volume 223, Number 4 (2009), ISSN: 0957-6509.

[12] W.M. Arshad, P. Thelin, T. Backstrom, C. Sadarangani, Use of transverse-flux machines in a free-piston generator, IEEE Internation Electric Machines and Drives Conference, 2003. IEMDC'03., Volume 3, page 1428, ISBN:0-7803-7817-2.

[13]P. Zheng, A. Chen, P. Thelin, W. M. Arshad, C. Sadarangani, Research on a Tubular Longitudinal Flux PM Linear Generator Used for Free-Piston Energy Converter" IEEE Transaction on Magnetics, Jan. 2007, ISSN: 0018-9646.

[14] Xu Zhaoping. Chang Siqin, Improved Moving Coil Electric Machine for Internal Combustion Linear Generator, IEEE Transactions on Energy Conversion, Volume 25, Issue 2, page 281 (2010), ISSN: 0885-8969.

[15]Kim Young-wook, Lim Jaewon, Choi Ho-Yong, et al, Starting mode analysis of tubular-type linear generator for free-piston engine with dynamic characteristics, International Conference on Electrical Machines and Systems, ICEMS, page 926 (2007), ISBN:978-89-86510-07-2.

[16] Jiabin Wang West, D. M. Howe, H.Z.-D. La Parra, W.M. Arshad, Design and Experimental Verification of a Linear Permanent Magnet Generator for a Free-Piston Energy Converter, IEEE Transaction on Energy Conversion, Volume 22, Issue 2 (2007), page 299, ISSN:0885-8969.

[17]Li Qing-feng, Jin Xiao, Zhen Huang, Flat-type permanent magnet linear alternator: A suitable device for a free piston linear alternator, Journal of Zhejiang University - Science A, 2009, Volume 10 , No. 3.

[18]W. Arof and H. Arof, Open Circuit Field Distribution and Induced Voltage of a Cylindrical Permanent Magnet Linear Generator, American Journal of Applied Sciences, vol. 4, no 11, page 912-917 (2007), ISSN: 1546-9239.

[19]C. A., Oprea, C. S., Martis, K. A., Biro, F. N. Jurca, Design and testing of a four-side permanent magnet linear generator prototype, International Conference on Electrical Machines (ICEM), Sept. 2010, ISBN 978-1-4244-4175-4. 